\title{
DAMPAK PELATIHAN ONLINE RESCHEDULE LIFESTYLE PASIEN HIPERTENSI TERHADAP PENINGKATAN PENGETAHUAN DAN KEMAMPUAN NERS FRESH GRADUATE DI MASA PANDEMI COVID -19
}

\author{
Windu Santoso', Sri Sudarsih ${ }^{2}$ \\ Email : srisudarsih.ws@gmail.com \\ 1,2 STIKes Bina Sehat PPNI Mojokerto, Indonesia
}

\begin{abstract}
The high mortality rate in hypertensive sufferers is one sign that the Indonesian people still do not understand the importance of adherence to medication and lifestyle changes. The purpose of this study was to determine the effect of online training on lifestyle rescheduling of hypertensive patients on the knowledge and abilities of fresh graduate nurses. The research design used a quasi-experimental pre-test post-test with a population of all Fresh Graduate Stikes Bina Sehat PPNI Mojokerto. The sample used was 30 respondents using simple random sampling. Data collection using a questionnaire. Data analysis was carried out with frequency distribution and then performed normality test using Kolmogorov Smirnoff to obtain data for the two normal variables. To determine the impact of online training on knowledge and abilities, the Paired t-test was conducted. Based on the results of the Paired T-Test on the impact of online training on knowledge, the value of $p=0.000<0.05$ was obtained and the results of the Paired T-Test on the impact of online training on ability obtained $p$-value $=0.001<0.05$. The results of the study prove that online training on Lifestyle Rescheduling has an impact on increasing the knowledge and abilities of respondents. Training in the form of interactive sessions and the use of various presentation methods and assistance in the application of lifestyle rescheduling of hypertensive patients can increase the knowledge and abilities of respondents.
\end{abstract}

\section{ABSTRAK}

Tingginya angka kematian pada penderita hipertensi merupakan salah satu tanda bahwa masyarakat Indonesia masih kurang memahami pentingnya kepatuhan dalam menjalankan pengobatan dan perubahan gaya hidup (lifestyle). Tujuan penelitian ini adalah untuk mengetahui dampak pelatihan online penyusunan reschedule lifestyle pasien hipetensi terhadap pengetahuan dan kemampuan Ners Fresh Graduate. Desain penelitian menggunakan quasi eksperimen pre-tes post-test dengan populasi seluruh Ners Fresh Graduate Stikes Bina Sehat PPNI Mojokerto. Sampel yang digunakan sebanyak 30 responden dengan menggunakan simpel random sampling. Pengumpulan data menggunakan kuesioner. Analisa data dilakukan dengan distribusi frekwensi dan selanjutnya dilakukan uji normalitas menggunakan Kolmogorof Smirnof sehingga didapatkan data ke dua variabel normal. Untuk mengetahui dampak pelatihan online terhadap pengetahuan dan kemampuan dilakukan uji Pired t-test. Berdasarkan hasil uji Paired $T$ Test dampak pelatihan online terhadap pengetahuan didapatkan $p$ value $=0,000<0,05$ dan hasil uji Paired $T$ Test dampak pelatihan online terhadap kemampuan didapatkan $p$ value $=0,001<0,05$. Hasil penelitian membuktikan bahwa pelatihan online tentang Penyusunan Reschedue lifestyle berdampak pada peningkatan pengetahuan dan kemampuan responden. Pelatihan yang berbentuk sesi-sesi interaktif dan menggunakan berbagai metode presentasi serta pendampingan dalam mengaplikasikan penyusunan reschedule lifestyle pasien hipertensi dapat meningkatkan pengetahuan dan kemampuan responden.

\section{ARTICLE INFO}

Keywords:

Ability; Hipertension; Knowledge; Lifestyle;

Reschedule

DOI:

10.24252/kesehatan.v14i2.19548

Kata kunci :

Kemampuan; hipertensi; Pengetahuan; Gaya

hidup; Menjadwalkan ulang

\section{Pendahuluan}

Hipertensi menjadi masalah utama kita semua, tidak hanya di Indonesia tetapi di dunia karena hipertensi merupakan salah satu pintu masuk atau faktor resiko penyakit seperti jantung, gagal ginjal, diabetes dan stoke (1). Hipertensi merupakan salah satu penyakit kardiovaskuler yang paling umum dan paling banyak di sandang masyarakat. Penyakit kardiovaskular ini menjadi penyebab nomor satu kematian di dunia setiap tahunnya (2). Tingginya angka kematian kardiovaskuler pada usia yang semakin muda, yang terutama berkaitan dengan hipertensi di Indonesia merupakan salah satu tanda bahwa masyarakat Indonesia masih kurang memahami 
pentingnya kepatuhan (compliance) dalam menjalankan pengobatan dan perubahan gaya hidup (lifestyle) (3).

Masa pandemi COVID-19 sekarang ini, orang dengan penyakit penyerta (komorbid) merupakan salah satu kelompok yang sangat rentan terpapar virus. Penyandang Penyakit Tidak Menular (PTM) salah satunya hipertensi jika terkonfirmasi COVID-19 berpotensi besar mengalami perburukan klinis sehingga meningkatkan risiko kematian. Hipertensi sangat mungkin dicegah dengan perubahan perilaku hidup bersih dan sehat. Pandemi COVID-19 ini bisa kita jadikan sebagai momentum untuk membudayakan gaya hidup sehat (4).

Jumlah penderita hipertensi di dunia terus meningkat setiap tahunnya, diperkirakan pada 2025 akan ada 1,5 miliar orang yang terkena hipertensi. Setiap tahun juga diperkirakan ada 9,4 juta orang meninggal akibat hipertensi dan komplikasi (Kemenkes 20200. Riskesdas 2018 menunjukkan prevalensi Penyakit hipertensi mengalami kenaikan jika dibandingkan dengan Riskesdas 2013, hipertensi naik dari 25,8\% menjadi 34,1\% (5). Data Badan Penyelenggara Jaminan Sosial (BPJS) kesehatan menyebutkan bahwa biaya pelayanan hipertensi mengalami peningkatan setiap tahunnya yaitu pada tahun 2016 sebesar 2,8 Triliun rupiah, tahun 2017 dan tahun 2018 sebesar 3 Triliun rupiah (2). Data Riskesdas 2018 pada penduduk usia 15 tahun keatas didapatkan data faktor risiko seperti proporsi masyarakat yang kurang makan sayur dan buah sebesar 95,5\%, proporsi kurang aktifitas fisik 35,5\%, proporsi merokok 29,3\%, proporsi obesitas sentral 31\% dan proporsi obesitas umum 21,8\%. Data tersebut diatas menunjukkan peningkatan jika dibandingkan dengan data RISKESDAS tahun 2013 (6).

Minimnya pengetahuan dan kemampuan Ners Fresh Graduate sebagai tenaga kesehatan tentang reschedule lifestyle pasien hipertensi akan menghambat dalam melakukan pendampingan pada penderita hipertensi sebagai upaya pencegahan dan pengendalian tekanan darah. Hal ini menjadi salah satu faktor hambatan dalam menjalankan tugas sebagai tenaga kesehatan (perawat) khususnya penanganan masalah hipertensi.

Berdasarkan hasil studi pendahuluan yang dilakukan pada 10 Ners Fresh graduate didapatkan data secara umum seluruhnya tahu tentang gaya hidup sehat pada pasien hipertensi namun saat diwawancara secara mendalam tentang komponen gaya hidup sehat pasien hipertensi terutama pada komponen mempertahankan berat badan ideal, aktivitas fisik, mengurangi asupan garam dan diet sehat serta mengurangi stress sebagian besar (90\%) memiliki pengetahuan pada rentang cukup dan kurang. Kemampuan menyusun reschedule lifestyle menunjukkan kemampuan pada rentang cukup dan kurang sebanyak $60 \%$.

Penanganan pasien hipertensi melalui program reschedule lifestyle diharapkan dapat menjadi salah satu upaya non farmakologi dalam pencegahan dan penanganan pasien hipertensi yang diharapkan akan membantu menurunkan dan mengendalikan tekanan darah pasien dalam batas nilai normal. Pelatihan tentang reschedule lifestyle diharapakan akan meningkatkan kemampuan kader dalam membantu sekelompok pasien hipertensi untuk menyusun rencana perubahan pola hidup sehat. Berdasarkan hal ini peneliti ingin mengetahui dampak pelatihan online penyusunan reschedule lifestyle pasien hipetensi terhadap pengetahuan dan kemampuan Ners Fresh Graduate.

\section{Metode Penelitian}

Penelitian ini menggunakan desain quasi eksperimen pre-tes post-test. Populasi dalam penelitian ini adalah seluruh Ners Fresh Graduate Stikes Bina Sehat PPNI Mojokerto. Dalam penelitian ini besar sampel yang digunakan adalah 30 responden. Teknik sampling yang digunakan adalah simpel random sampling dengan kriteria 1) bersedia menjadi responden selama penelitian berlangsung, 2) bersedia mengikuti seluruh kegiatan pelatihan, 3) memiliki salah satu keluarga yang menderita hipertensi.

Kegiatan pengambilan data dilakukan selama 2 hari. Hari pertama pengambilan data pada grup Redesign lifestyle 1 dan hari ke dua pada grup Redesign lifestyle 2. Responden dibagi menjadi 2 kelompok kecil untuk memudahkan pengelolaan pelatihan dan dengan kelompok kecil 
diharapkan dapat terjalin interaksi yang baik antara peserta pelatihan (reponden) dengan narasumber sehingga dapat lebih memahami materi yang disampaikan.

Setelah responden menyatakan bersedia menjadi responden dilanjut dengan pengisian kuesioner pengetahuan dan kemampuan (pre test) melalui google form. Kemudian responden diberikan pelatihan tentang Reschedule Lifestyle pasien hipertensi. Materi pelatihan yang diberikan pada responden terdiri dari 2 materi yaitu tentang Gaya Hidup Sehat Penderita hipertensi dan tentang Reschedule Lifestyle Penderita Hipertensi. Pada akhir kegiatan pelatihan respoden mengisi kembali kuesioner pengetahuan dan kemampuan (post test) melalui google form.

Analisa data dilakukan dengan distribusi frekwensi untuk mendapatkan gambaran tentang pengetahuan dan kemampuan responden tentang penyusunan reshedule lifestyle pasien hipertensi. Selanjutnya dilakukan uji normalitas dengan menggunakan Kolmogorof Smirnof sehingga didapatkan data ke dua variabel normal. Untuk mengetahui dampak pelatihan online terhadap pengetahuan dan kemampuan dilakukan uji Pired $t$-test.

\section{Hasil Penelitian}

Responden dalam penelitian ini berusia antara 23-25 tahun dan di atas 53,3\% berada pada umur 23 tahun. Jenis kelamin responden 63,3\% adalah berjenis kelamin perempuan. Pada penelitian ini responden yang menyatakan pernah mendapat informasi tentang reschedule lifestyle pada hipertensi adalah $80 \%$. Dapat dikatakan bahwa $26,7 \%$ responden mendapatkan informasi tentang reschedule lifestyle pasien hipertensi dari webinar. Data selengkapnya dapat dilihat pada tabel dibawah ini :

Tabel 1 Distribusi Frekuensi berdasarkan karakteristik

\begin{tabular}{lcc}
\hline Umur & Frekuensi & \% \\
\hline 23 tahun & 16 & 53,3 \\
\hline 24 tahun & 12 & 40,0 \\
\hline 25 tahun & 2 & 6,7 \\
\hline Jenis Kelamin & & \\
\hline Perempuan & 19 & 63,3 \\
Laki-laki & 11 & 36,7 \\
& & \\
Pernah Dapat Informasi & & \\
\hline Ya & 24 & 80,0 \\
Tidak & 6 & 20,0 \\
& & \\
\hline Sumber Informasi & & \\
\hline Tidak pernah & 6 & 20,0 \\
Webinar & 8 & 26,7 \\
Internet & 5 & 16,7 \\
Seminar & 1 & 3,3 \\
Buku dan materi kuliah & 4 & 13,3 \\
& 6 & 20,0 \\
\hline Total & 30 & 100 \\
\hline
\end{tabular}

Pengetahuan responden tentang perencanaan gaya hidup sehat sebelum pelatihan online sebesar 50\% cukup dan setelah pelatihan $40 \%$ dalam kategori baik. Pengetahuan responden tentang upaya mempertahankan $\mathrm{BB}$ ideal sebelum pelatihan online dominan memiliki pengetahuan kurang dan setelah pelatihan $40 \%$ responden memiliki pengetahuan baik. 
Responden dominan memiliki penegetahuan kurang dalam meanajemen stres sebelum pelatihan yaitu sebanyak $70 \%$, dan setelah pelatihan $50 \%$ responden memiliki pengetahuan baik. Pengetahuan responden tentang periksa tekanan darah (TD) secara rutin dominan memiliki pengetahuan baik $73,4 \%$ dan setelah pelatihan meningkat menjadi $96,7 \%$. Pengetahuan responden tentang upaya berhenti merokok sebelum pelatihan online hanya 3,3\% responden yang memiliki pengetahuan baik dan setelah mengikuti pelatihan $50 \%$ responden yang memiliki pengetahuan baik. Sebelum pelatihan 50\% responden memiliki pengetahuan cukup tentang aktifitas fisik teratur dan setelah pelatihan terjadi peningkatan tingkat pengetahuan menjadi dominan pada tingkat cukup sebesar $40 \%$, namun kenaikan pada tingkat baik dari 3,3\% meningkat menjadi 33,3\%. Pengetahuan responden tentang diet dan mengurangi asupan garam dominan berada pada tingkat pengetahuan cukup yaitu $76,6 \%$ sebelum pelatihan dan setelah pelatihan meningkat dominan pada level pengetahuan cukup sebesar 46,7\%, namun responden yang memiliki pengetahuan baik juga meningkat pengetahuannnya dari $6,7 \%$ menjadi 43,3\%. Data selengkapnya dapat dilihat pada tabel dibawah ini:

Tabel 2 Distribusi Frekuensi Pengetahuan Responden Tentang Reschedule LifeStyle Berdasarkan Pre Test dan Pos Test

\begin{tabular}{|c|c|c|c|c|}
\hline \multirow{2}{*}{$\begin{array}{c}\text { Pengetahuan tentang } \\
\text { Penyusunan Gaya Hidup Sehat }\end{array}$} & \multicolumn{2}{|c|}{ Pre Test } & \multicolumn{2}{|c|}{ Post Test } \\
\hline & $\mathrm{f}$ & $\%$ & $\mathrm{f}$ & $\%$ \\
\hline \multicolumn{5}{|l|}{ Perencanaan gaya hidup sehat } \\
\hline - Kurang & 8 & 26.7 & 5 & 16.7 \\
\hline - Cukup & 15 & 50.0 & 7 & 23.3 \\
\hline - Baik & 7 & 23.3 & 18 & 40.0 \\
\hline \multicolumn{5}{|l|}{ Mepertahankan BB ideal } \\
\hline - Kurang & 29 & 96.7 & 18 & 60 \\
\hline - Cukup & 0 & 0 & 0 & 0 \\
\hline - Baik & 1 & 3.3 & 12 & 40 \\
\hline \multicolumn{5}{|l|}{ Periksa TD secara rutin } \\
\hline - Kurang & 4 & 13.3 & 1 & 3.3 \\
\hline - Cukup & 4 & 13.3 & 0 & 0 \\
\hline - Baik & 22 & 73.4 & 29 & 96.7 \\
\hline \multicolumn{5}{|l|}{ Tidak merokok } \\
\hline - Kurang & 29 & 96.7 & 15 & 50.0 \\
\hline - Cukup & 0 & 0.0 & 0 & 0 \\
\hline - Baik & 1 & 3.3 & 15 & 50.0 \\
\hline \multicolumn{5}{|l|}{ Aktivitas fisik teratur } \\
\hline - Kurang & 14 & 46.7 & 8 & 28.7 \\
\hline - Cukup & 15 & 50.0 & 12 & 40.0 \\
\hline - Baik & 1 & 3.3 & 10 & 33.3 \\
\hline \multicolumn{5}{|l|}{$\begin{array}{l}\text { Mengurangi asupan garam + } \\
\text { diet sehat }\end{array}$} \\
\hline - Kurang & 5 & 16.7 & 3 & 10.0 \\
\hline - $\quad$ Cukup & 23 & 76.6 & 14 & 46.7 \\
\hline - Baik & 2 & 6.7 & 13 & 43.3 \\
\hline \multicolumn{5}{|l|}{ Mengurangi stres } \\
\hline - Kurang & 21 & 70 & 15 & 50 \\
\hline - Cukup & 0 & 0 & 0 & 0 \\
\hline - $\quad$ Baik & 9 & 30 & 15 & 50 \\
\hline
\end{tabular}


Kemampuan responden dalam tahap persiapan terjadi peningkatan antara pre dan post pelatihan online dari $26,6 \%$ menjadi $50 \%$. Pada identifikasi perilaku lama kemampuan responden dominan pada level baik yaitu sebanyak $60 \%$ dan setelah pelatihan online tetap $60 \%$ yang baik, namun pada responden dengan kemampuan cukup sebayak $0 \%$ meningkat menjadi 33,3\%. Pada identifikasi perilaku baru distribusi responden yang memiliki kemampuan baik hanya $10 \%$ dan meningkat menjadi $43,3 \%$. Pada penyusunan reschedule lifestyle distribusi responden yang memiliki kemampuan kurang sebesar $50 \%$ dan setelah pelatihan terjadi penurunan menjadi $26,7 \%$, namun pada kemampuan baik mengalami penungkatan dari 3,3\% meningkat menjadi 30\%. Data selengkapnya dapat dilihat pada tabel di bawah ini :

Tabel 3 Distribusi Frekuensi Kemampuan Responden Tentang Reschedule Life Style Berdasarkan Pre Test dan Pos Test

\begin{tabular}{|c|c|c|c|c|}
\hline \multirow{2}{*}{$\begin{array}{c}\text { Kemampuan tentang Reschedul } \\
\text { lifestyle }\end{array}$} & \multicolumn{2}{|c|}{ Pre Test } & \multicolumn{2}{|c|}{ Post Test } \\
\hline & f & $\%$ & f & $\%$ \\
\hline \multicolumn{5}{|l|}{$\begin{array}{l}\text { Persiapan, penjelasan tujuan dan } \\
\text { manfaat reschedule life style }\end{array}$} \\
\hline - Kurang & 11 & 36.7 & 5 & 16.7 \\
\hline - $\quad$ Cukup & 11 & 36.7 & 10 & 33.3 \\
\hline - Baik & 8 & 26.6 & 15 & 50.0 \\
\hline \multicolumn{5}{|l|}{ Identifikasi perilaku lama } \\
\hline - Kurang & 12 & 40.0 & 2 & 6.7 \\
\hline - Cukup & 0 & 0 & 10 & 33.3 \\
\hline - Baik & 18 & 60.0 & 18 & 60.0 \\
\hline \multicolumn{5}{|l|}{ Identifikasi perilaku baru } \\
\hline - Kurang & 2 & 6.7 & 4 & 13.4 \\
\hline - Cukup & 25 & 83.3 & 13 & 43.3 \\
\hline - $\quad$ Baik & 3 & 10.0 & 13 & 43.3 \\
\hline \multicolumn{5}{|l|}{$\begin{array}{l}\text { Penyusunan rencana dan } \\
\text { modifikasi/koreksi }\end{array}$} \\
\hline - Kurang & 15 & 50.0 & 8 & 26.7 \\
\hline - Cukup & 14 & 46.7 & 13 & 43.3 \\
\hline - Baik & 1 & 3.3 & 9 & 30.0 \\
\hline
\end{tabular}

Data pre test dan post test dengan Kolmogorof Smirnov pada mean residual data pre test dan post test pengetahuan dan kemampuan di dapatkan $p$ value $=0,200$, maka data normal, sehingga dilanjutkan dengan uji Paired Test.

Berdasarkan hasil uji Paired T Test di daptakan rata-rata pre test pengetahuan 58,80 dengan standar deviasai 7,586 dan post test 73,60 dengan standar deviasai 14,989, dengan $p$ value $=0,000<0,05$, maka kita dapat disimpulkan bahwa terdapat perbedaan yang nyata antara hasil pelatihan online pada pengetahuan tentang penyusunan reschedule lifestyle pasien hipertensi pada ners fresh graduate. Dalam penelitian ini terbukti bahwa pelatihan online tentang reschedule lifestyle pasien hipertensi yang dilakukan pada ners fresh graduate berdampak pada peningkatan pengetahuan. Data selengkapnya dapat dilihat pada tabel dibawah ini : 
Dampak Pelatihan Online Reschedule Lifestyle Pasien Hipertensi terhadap Peningkatan Pengetahuan dan Kemampuan Ners Fresh Graduate di Masa Pandemi Covid -19

Tabel 4 Perbedaaan Pre Test dan Post Test Penegtahuan tentang

Penyusunan Reschedule Lifestyle pada Ners Fresh Graduate

\begin{tabular}{|c|c|c|c|c|c|c|}
\hline $\begin{array}{c}\text { Score } \\
\text { Pengetahuan } \\
\text { Redesign } \\
\text { Lifestyle }\end{array}$ & $\mathbf{N}$ & Mean & SD & $\begin{array}{l}\text { Min- } \\
\text { Max }\end{array}$ & $\begin{array}{c}\text { Mean } \\
\text { Difference }\end{array}$ & $\begin{array}{c}P \\
\text { value }\end{array}$ \\
\hline Pre-test & 30 & 58,80 & 7,586 & $\begin{array}{l}44- \\
72\end{array}$ & \multirow{2}{*}{$-14,800$} & \multirow{2}{*}{0,000} \\
\hline Post-test & 30 & 73,60 & 14,989 & $\begin{array}{l}40- \\
96\end{array}$ & & \\
\hline
\end{tabular}

Berdasarkan hasil uji Paired T Test di daptakan rata-rata pre test kemampuan 67,17 dengan standar deviasai 9,973 dan post test 76,00 dengan standar deviasai 13,157 , serta $p$ value $=0,001<0,05$, maka kita dapat disimpulkan bahwa terdapat perbedaan yang nyata antara hasil pelatihan online pada kemampuan tentang penyusunan reshedule lifestyle pasien hipertensi pada ners fresh graduate. Dalam penelitian ini terbukti bahwa pelatihan online tentang reschedule lifestyle yang dilakukan pada ners fresh graduate berdampak pada peningkatan kemampuan. Data selengkapnya dapat dilihat pada tabel di bawah ini :

Tabel 5 Perbedaan Pre Test dan Post Test Kemampuan tentang

Penyusunan Reschedul Lifestyle pada Ners Fresh Graduate

\begin{tabular}{|c|c|c|c|c|c|c|}
\hline $\begin{array}{c}\text { Score } \\
\text { Kemampuan } \\
\text { Redesign Life } \\
\text { style }\end{array}$ & $\mathbf{N}$ & Mean & SD & $\begin{array}{l}\text { Min - } \\
\text { MaX }\end{array}$ & $\begin{array}{c}\text { Mean } \\
\text { Difference }\end{array}$ & $\begin{array}{c}P \\
\text { value }\end{array}$ \\
\hline Pre-test & 30 & 67,17 & 9,973 & $50-80$ & \multirow{2}{*}{$-8,833$} & \multirow{2}{*}{0,001} \\
\hline Post-test & 30 & 76,00 & 13,157 & $50-100$ & & \\
\hline
\end{tabular}

\section{Diskusi}

\section{Pengetahuan tentang reshedule lifestyle sebelum dan sesudah pelatihan online}

Dalam penelitian ini, distribusi pengetahuan responden tentang reschedule life style pada saat pre test dominan pada level cukup sebesar $76,7 \%$. Setelah mengikuti pelatihan online pengetahuan responden yang cukup menurun menjadi $40 \%$, namun pada level pengetahuan baik meningkat dari $0 \%$ menjadi $40 \%$.

Sebagian besar pengetahuan manusia di peroleh melalui pengindraan (mata, hidung, telinga dan sebagainya). Dengan sendirinya pada waktu pengindraan sehingga menghasikan pengetahuan tersebut sangat dipengaruhi oleh intensitas perhatian dan persepsi terhadap obyek. Sebagian besar pengetahuan seseorang diperoleh melalui indra pendengaran (telinga), dengan indra penglihatan (mata). Pengetahuan seseorang terhadap obyek mempunyai intensitas atau tingkat yang berbeda-beda (7). Ada beberapa faktor yang mempengaruhi tingkat pengetahuan diantaranya pendidikan, pekerjaan, umur, lingkungan, sosial budaya, jenis kelamin dan sumber informasi (8).

Penelitian pada 200 partisipan didapatkan $(73,0 \%)$ peserta memiliki pengetahuan yang baik, $182(66,4 \%)$ memiliki sikap baik dan 136 (49,6 \%) memiliki praktik yang baik tentang modifikasi gaya hidup yang direkomendasikan untuk manajemen hipertensi. (9). Berdasarkan penelitian ASHAs tentang pengetahuan hipertensi meningkat dari skor rata-rata 64\% pada awal menjadi $76 \%$ pasca pelatihan dan $84 \%$ setelah intervensi 3 bulan. Petugas penelitian yang 
mengamati pertemuan masyarakat melaporkan bahwa ASHA menyampaikan materi secara efektif dalam pelatihan tersebut sehingga materi mudah dipahami dan bermanfaat dalam mendidik anggota masyarakat yang mengalami hipertensi (10)

Pengetahuan responden tentang reschedule lifestyle dominan pada tingkat cukup disebabkan karena pengetahuan responden dipengaruhi oleh intensitas perhatian dan persepsi pada saat menerima informasi, walaupun sebagian besar responden telah mendapatkan informasi tentang reschedule lifestyle dan informasi lebih banyak didapat dari webinar / seminar sehingga akan mempengaruhi tingkat pengetahuan responden. Informasi yang didapatkan dari webinar bersifat satu arah, hal tersebut menyebabkan interaksi antara pemberi materi dan peserta menjadi berkurang sehingga akan sulit bagi peserta untuk mendapatkan penjelasan lebih lanjut mengenai materi yang sukar dipahami.

Respon menerima dan memahami materi dari peserta berdasarkan tingkat pemahaman yang berbeda-beda, tergantung kepada kemampuan peserta. Beberapa orang mungkin dapat menangkap materi dengan lebih cepat hanya dengan membaca, namun ada juga yang membutuhkan waktu lebih lama sampai benar-benar paham. Bahkan ada juga yang membutuhkan penjelasan dari orang lain agar dapat memahami materi yang dipelajari. Setelah mengikuti pelatihan online pengetahuan responden mengalami peningkatan hal ini dikarenakan responden yang sebelumnya sudah pernah mendapatkan informasi tentang reschedule lifestyle kemudian diberikan pelatihan online tentang topik yang sama sehingga responden mendapatkan informasi berulang dan tentunya akan mempengaruhi level pengetahuan responden.

Penyebab lain dari meningkatnya pengetahuan Ners fresh graduate tentang reschedule lifestyle disebabkan oleh pelaksanaan pelatihan yang dibagi menjadi dua tahap sehingga jumlah peserta pelatihan hanya sedikit yaitu 15 orang setiap tahap. Sedikitnya jumlah peserta dalam pelatihan dapat meningkatkan keaktifan responden sehingga dapat membantu meningkatkan pemahan responden. Hal ini sejalan dengan pendapat Yaldez Zein el diN tahun 2019 yang mengatakan bahwa sedikitnya jumlah peserta (sekitar 15-20) dalam pelatihan dapat memfasilitasi dan meningkatkan pemahaman masing-masing peserta juga memungkinkan peserta untuk bertanya dan terlibat dalam semua aktivitas (11)

\section{Kemampuan tentang reshedule lifestyle sebelum dan sesudah pelatihan online}

Kemampuan penyusunan reschedule lifestyle terbukti ada peningkatan kemampuan pada level baik dari $16,7 \%$ menjadi $43,3 \%$, sedang pada level kemampuan cukup setelah pelatihan online menurun dari $60 \%$ menjadi $46,7 \%$

Pelatihan merupakan metode atau cara yang digunakan untuk membangun kemampuan dan meningkatkan keterampilan serta pengetahuan dengan memberikan informasi yang baru untuk melakukan pekerjaan secara efisien (12). Pelatihan merupakan upaya sistematis mengembangkan keterampilan - keterampilan tertentu dan mempengaruhi perilaku. Pelatihan diperlukan pada saat terjadi kesenjangan antara tuntutan pekerjaan dengan kemampuan. Tujuan pendidikan dan pelatihan adalah untuk meningkatkan kemampuan dan keterampilan (13).

Perawat berada di garis depan dalam kesehatan masyarakat dan membutuhkan banyak waktu untuk mempromosikan kesehatan tentang perilaku gaya hidup bagi pasien dan keluarganya. Namun studi tentang perilaku gaya hidup sehat menunjukkan bahwa masyarakat banyak yang tidak patuh terhadap pedoman kesehatan masyarakat yang terkait dengan aktivitas fisik, diet, merokok dan konsumsi alkohol (14). Berdasarkan hasil penelitian menyatakan bahwa gabungan pengaturan aktivitas fisik yang baik dengan pola makan terbukti ada hubungan dengan berat badan dan obesitas, penelitian ini dilakukan pada 153 orang dan didapatkan 59 orang yang obesitas, dengan cara melaporkan sendiri pola makan dan aktivitas fisik sesuai dengan teori perencanaan perilaku (15). 
Penelitian lain di Swedia menunjukkan penurunan tekanan darah sistolik antara 4-5 mmHg pada pasien yang menerima konseling perubahan perilaku (16). Penelitian Hadiza pada 104 hanya $31,7 \%$ pasien memiliki pengetahuan baik, dan hanya 59 (56,7\%) yang memiliki kepatuhan yang baik, sehingga tingkat pengetahuan dan praktik modifikasi gaya hidup dalam pengendalian tekanan darah pada populasi yang diteliti tergolong rendah. Peneliti merekomendasikan pentingnya strategi terpadu untuk meningkatkan kesadaran, pengetahuan, dan implementasi modifikasi gaya hidup pada pasien hipertensi (17).

Responden dalam penelitian ini merupakan seorang perawat yang perlu menyadari bahwa perilaku pola hidup sehat bagi penderita hipertensi dan masyarakat sangat penting sehingga perawat perlu memahami tentang reschedule lifestyle sehingga dapat membantu dan mendampingi penderita hipertensi dalam menyusun lifestyle mereka. Pelatihan reschedule lifestyle merupakan salah satu upaya untuk meningkatkan kemampuan perawat dalam membantu penderita hipertensi menyusun pola hidup sehat. Dalam penelitian ini kemampuan responden (ners fresh graduate) mengalami peningkatan dikarenakan pelatihan yang dilaksanakan disertai dengan pendampingan penyusunan reschedule lifestyle dengan bantuan kartu rencana perubahan gaya hidup sehat (RPGHS) yang berlangsung selama tiga hari. Dalam kartu RPGHS tersebut responden diharapkan mampu menyusun lifestyle penderita (reschedule lifestyle) berdasarkan indikator lifestyle penderita hipertensi yang meliputi melakukan aktivitas fisik, mengurangi asupan garam, manajemen stres, mempertahankan berat badan ideal, berhenti merokok dan periksa tekanan darah secara rutin. Pemberian materi yang terkait dengan reschedule lifestyle dan disertai dengan pendampingan membuat responden lebih memahami sehingga dapat mengaplikasikan pengetahuannya dalam reshedule lifestyle penderita hipertensi yang sangat dibutuhkan untuk membantu penderita hipertensi menyusun pola hidup sehat mereka.

Dampak Pelatihan online pada Peningkatan Pengetahuan dan Kemampuan Ners Fresh Graduate dalam Penyusunan Reschedule Lifestyle

Penelitian ini telah membuktikan bahwa terjadi peningkatan signifikan pada pengetahuan dan kemampuan ners Fresh Graduate dalam penyusunan Reschedule Lifestyle pada penderita hipertensi dengan nilai $p$ value 0,000 pada variabel pengetahuan dan 0,001 pada variabel kemampuan, artinya pelatihan online yang dilaksanakan dapat meningkatkan pengetahuan dan kemampuan ners fresh graduate.

Kegiatan pelatihan berkontribusi untuk meningkatkan kemampuan, keterampilan, pengetahuan dan sikap karena individu yang terlatih melakukan tugasnya dengan efisien dibandingkan individu yang tidak terlatih (18). Peran perawat sebagai fasilitator perubahan pola hidup sehat pada pasien. Ketika bertindak sebagai fasilitator, perawat dapat membantu pasien hipertensi dalam merencanakan perubahan pola hidup sehat dan menentukan pola hidup sehat yang paling tepat untuk dirinya. Penelitian tentang Intervensi perubahan gaya hidup (lifestyle), fasilitator membantu peserta mengembangkan kemampuan secara interaktif mengatasi suasana hati yang berfluktuasi dan perubahan motivasi sehingga makan secara sehat dan berolahraga secara teratur.

Penelitian Oyewole yang dilakukan pada 30 responden dengan hipertensi dengan hasil terdapat perbedaan yang significan pada pengetahuan dan modifikasi gaya hidup (19). Dalam penelitian Preis tentang pentingnya pemberian motivasi perubahan perilaku, pola hidup lebih sehat (20). Intervensi perilaku berdampak baik pada kelompok beresiko lebih efektif terhadap faktor resiko pemyakit, pola makan dan pola aktivitas (21). Merupakan kebutuhan mendesak di Eropa bagi pusat pencegahan penyakit pembuluh darah dan jantung untuk memiliki tim multi disiplin profesional perawatan kesehatan, yang berfokus pada semua aspek gaya hidup dan manajemen faktor risiko untuk mengurangi risiko dan meningkatkan standar pencegahan penyakit jantung dan pembuluh darah (22).

Penelitian dengan intervensi gaya hidup termasuk olahraga, penurunan berat badan, dan nutrisi optimal berpotensi menurunkan tekanan darah secara substansial. Bukti didapatkan agar 
perubahan perilaku berhasil, intervensi harus dikaitkan dengan program terstruktur yang dirancang untuk memfasilitasi perubahan perilaku (10). Penelitian yang berfokus pada kebijakan kesehatan di bidang anti-obesitas biasanya berfokus pada menasihati atau 'mendorong' individu untuk memperbaiki tubuh yang tidak sehat, dan dengan demikian membebani, melalui perilaku pribadi seperti makan lebih sedikit dan berolahraga lebih banyak (23). Keuntungan melaksanakan gaya hidup sehat dapat menurunkan tekanan darah (24). Sejumlah besar bukti epidemiologis menunjukkan bahwa penyakit yang paling umum di masyarakat maju, termasuk sindrom metabolik, terkait erat dengan faktor gaya hidup, terutama merokok, kebiasaan makan yang tidak sehat, tidak aktif secara fisik dan stress (25).

Untuk mencapai tekanan darah sistolik kurang dari $140 \mathrm{mmHg}$ dan tekanan darah diastolik kurang dari $90 \mathrm{mmHg}$ perlu dilakukan upaya gabungan yang meliputi kepatuhan terhadap pengobatan, aktivitas fisik reguler, menghindari penggunaan alkohol, peningkatan konsumsi sayuran dan buah-buahan, dan penurunan konsumsi natrium dan lemak makanan (26). Pemberian edukasi pada pasien hipertensi, diharapkan juga dapat meningkatkan perubahan gaya hidup dan kepatuhan pengobatan, sehingga dapat menghambat komplikasi seperti stroke, gagal ginjal, dan infark miokard (27).

Penelitian menunjukkan bahwa pengetahuan dan kemampuan responden tentang reschedule lifestyle penderita hipertensi meningkat secara signifikan setelah mengikuti pelatihan dibandingkan sebelumnya. Hal ini dapat dikarenakan pelatihan yang berbentuk sesi-sesi interaktif dan menggunakan berbagai metode presentasi serta pendampingan kepada responden dalam mengaplikasikan penyusunan reschedule lifestyle penderita hipertensi yang hasilnya dapat meningkatkan pengetahuan dan kemampuan responden. Peningkatan pengetahuan dan kemampuan ners fresh graduate sangat penting untuk membantu perubahan perilaku hidup sehat dan memberikan motivasi pada kelompok beresiko khususnya penderita hipertensi.

Penatalaksanaan hipertensi yang dilakukan merupakan upaya pengurangan resiko naiknya tekanan darah. Upaya yang dilakukan meliputi penatalaksanaan farmokologis (obat-obatan) dan nonfarmakologis (memodifikasi gaya hidup). Menerapkan pola hidup sehat yang dianjurkan berupa melakukan aktivitas fisik, mengurangi asupan garam, manajemen stres, mempertahankan berat badan ideal, berhenti merokok dan periksa tekanan darah secara rutin dalam kehidupan sehari - hari telah terbukti dapat menurunkan tekanan darah.

Perawat sebagai salah satu petugas kesehatan memiliki peran dalam mengubah perilaku pola hidup sehat (lifestyle) penderita hipertensi dalam rangka menghindari komplikasi atau memperkecil resiko dari penyakit yang diderita. Peran perawat sebagai educator (pendidik) dalam masalah lifestyle dapat membantu pasien hipertensi mengenal kesehatan dan memelihara kesehatannya. Informasi kesehatan yang terkait dengan lifestyle pasien hipertensi yang diberikan oleh perawat bertujuan meningkatkan pengetahuan penderita hipertensi sehingga menyadari pentingnya penanganan hipertensi serta membangun sikap yang positif agar dapat melakukan perawatan hipertensi secara mandiri yang pada akhirnya dapat mencegah kemungkinan terjadinya komplikasi. Peran perawat dalam melakukan promosi kesehatan tentang lifestyle pasien hipertensi sangat mempengaruhi perilaku masyarakat agar terbentuknya perilaku hidup sehat sebagai tindakan preventif terhadap penyakit hipertensi.

\section{Kesimpulan}

Pelatihan online tentang reschedule lifestyle pasien hipertensi yang dilakukan pada ners fresh graduate berdampak pada peningkatan pengetahuan dan kemampuan.

\section{Daftar Pustaka}

1. Kemenkes RI. Hipertensi Penyakit Paling Banyak Diidap. 2019; Available from: https://sehatnegeriku.kemkes.go.id/baca/rilis-media/20190517/5130282/hipertensipenyakit-paling-banyak-diidap-masyarakat/

2. Kemenkes RI. Hipertensi penyakit paling banyak diidap masyarakat [Internet]. 2019. 
Dampak Pelatihan Online Reschedule Lifestyle Pasien Hipertensi terhadap Peningkatan Pengetahuan dan Kemampuan Ners Fresh Graduate di Masa Pandemi Covid -19

Available from: http://www.depkes.go.id/article/view/19051700002

3. Rokom. Kendalikan hipertensi [Internet]. 2014. Available from: http://sehatnegeriku.kemkes.go.id/baca/rilis- media/20140108/199549/kendalikanhipertensi-galakkan-progra/

4. Kemenkes RI. Panduan adaptasi kebiasaan baru dalam pencegahan dan pengendalian penyakit tidak menular. 2020.

5. Kemenkes RI. Hasil Utama Riskesdas 2018. 2018; Available from: http://www.depkes.go.id/resources/download/info-terkini/hasil-riskesdas-2018.pdf

6. Kemenkes RI. Potret Sehat Indonesia dari Riskesdas 2018 [Internet]. 2019. Available from: http://www.depkes.go.id/article/view/18110200003/potret-sehat- indonesia-daririskesdas-2018.html

7. Notoatmodjo S. Ilmu Perilaku Kesehatan. Jakarta: Rineka Cipta; 2014.

8. Wawan A, Dewi. Teori \& Pengukuran Pengetahuan, Sikap dan Perilaku Manusia. Yogyakarta: Nuha Medika; 2011.

9. Bogale S, Mishore KM, Tola A, Mekuria AN, Ayele Y. Knowledge, attitude and practice of lifestyle modification recommended for hypertension management and the associated factors among adult hypertensive patients in Harar, Eastern Ethiopia. SAGE Open Med. 2020;8:205031212095329.

10. Blumenthal JA, Sherwood A, Smith PJ, Mabe S, Watkins L. Lifestyle modification for resistant hypertension: The TRIUMPH randomized clinical trial. Am Heart J [Internet]. 2015;170(5):986-994.e5. Available from: http://dx.doi.org/10.1016/j.ahj.2015.08.006

11. Lucy Abuelela, Azza Ibrahim, Abdelkader Habiba, Yaldez K. ZeinEldin. Impact of training program on nurses ' knowledge regarding professional values in Damanhour fever hospital. 2019;(September):51-61.

12. Jagero N, Komba HV, Mlingi MN. Relationship between on the Job Training and Employees' Performance in Courier Companies in Dar es Salaam, Tanzania. Int J Humanit Soc Sci. 2012;2(22):114-20.

13. Syafitri A\& wirman. Manajemen Sumber Daya Manusia Dalam Organisasi Publik. Sumedang: IPDN Press; 2014. 114 p.

14. Stanulewicz N, Knox E, Narayanasamy M, Shivji N, Khunti K, Blake H. Effectiveness of lifestyle health promotion interventions for nurses: A systematic review. Int J Environ Res Public Health. 2020;17(1).

15. Chevance G, Caudroit J, Romain AJ, Boiché J, Chevance G, Caudroit J, et al. The adoption of physical activity and eating behaviors among persons with obesity and in the general population: the role of implicit attitudes within the Theory of Planned Behavior. 2016;8506(March).

16. Lönnberg L, Ekblom-Bak E, Damberg M. Improved unhealthy lifestyle habits in patients with high cardiovascular risk: results from a structured lifestyle programme in primary care. Ups J Med Sci [Internet]. 2019;124(2):94-104. Available from: https://doi.org/10.1080/03009734.2019.1602088

17. Hadiza S, akasai AM, Mijinyawa MS. Factor analysis of knowledge, attitude and practice of life style modification measures among hypertensive patients in North - Western Nigeria. J Med Res. 2017;3(2):74-8.

18. Abogsesa AS, Kaushik G. Impact of Training and Development on Employee Performance. Int J Civ Engagem Soc Chang. 2018;4(3):53-68.

19. Oyewole $\mathrm{O}$, Olorunfemi $\mathrm{O}$, Ojewole $\mathrm{F}$, Olawale $\mathrm{M}$. Effect of a training programme on knowledge and practice of lifestyle modification among hypertensive patients attending out-patient clinics in lagos. Iran J Nurs Midwifery Res. 2020;25(1):58-64.

20. Preis MA, Zellerhoff M, Brockmeyer T. Approach bias modification training to increase physical activity: A pilot randomized controlled trial in healthy volunteers. J Health Psychol. 2020;

21. Dombrowski SU, Avenell A, Sniehott FF. Behavioural interventions for obese adults with additional risk factors for morbidity: Systematic review of effects on behaviour, weight and disease risk factors. Obes Facts. 2010;3(6):377-96. 
22. Kotseva K, Bacquer D De, Backer G De, Jennings C, Gyberg V, Abreu A, et al. Lifestyle and risk factor management in people at high risk of cardiovascular disease . A report from the European Society of Cardiology European Action on Secondary and Primary Prevention by Intervention to Reduce Events ( EUROASPIRE ) IV cross-sectional. 2016;

23. Bombak A, Monaghan LF, Rich E. Dietary approaches to weight - loss , Health At Every - Size ( and beyond : rethinking the war on obesity. Soc Theory Heal [Internet]. 2019;17(1):89108. Available from: https://doi.org/10.1057/s41285-018-0070-9

24. WHO. Healthy lifestyles for patients with hypertension. 2017;1-32. Available from: http://apps.who.int/iris/bitstream/10665/254746/2/9789290617983-hyp-mod2eng.pdf?ua=1

25. Ensenyat A, Espigares-Tribo G, Machado L, Verdejo FJ, Rodriguez-Arregui R, Serrano J, et al. Metabolic risk management, physical exercise and lifestyle counselling in low-active adults: Controlled randomized trial (BELLUGAT). BMC Public Health. 2017;17(1):1-16.

26. Jones S. A comparison of hypertension management perceptions, knowledge and stage of change among hospital employees. Diss Abstr Int Sect A Humanit Soc Sci [Internet]. 2016;77(4-A(E)). Available from: http://search.ebscohost.com/login.aspx?direct=true\&db=psyh\&AN=2016-37856199\&site=ehost-live

27. Shaleena. Hypertension Management Through Patient Education. 2015; 